\title{
Viktor Frankl: o sentido da Logoterapia e sua atualidade contextual
}

\section{Viktor Frankl: the meaning of logotherapy and his present contectual}

Cristiano de Jesus Andrade*

\section{Resumo}

Viktor Emil Frankl foi médico, austríaco e fundador da escola da Logoterapia, que explora o sentido existencial do indivíduo e a dimensão espiritual da existência. A autenticidade do trabalho proposto pelo autor em questão tem seu alicerce em sua experiência vivida em quatro campos de concentração nazistas. A Logoterapia parte da dimensão espiritual para abordar sua relação com as outras dimensões da vida. Estuda as situações específicas da esfera da existência do indivíduo, sem negligenciar ou negar os conflitos, sejam eles expressos por sintomas somáticos ou psicológicos. Constitui uma linha de psicoterapia centrada no sentido e que considera sua tarefa ajudar o paciente a encontrar sentido em sua vida tornando a principal força motivadora no ser humano. Quanto à origem do sentimento de falta de sentido, pode-se dizer, ainda que as pessoas tenham o suficiente com o que viver, mas não têm nada por que viver; têm os meios, mas não têm o sentido. Esse tem que ser encontrado pela própria pessoa, mas não dentro dela, porque isto iria contra a lei da auto-transcendência do existir humano. Ao tentar responder à questão do sentido da vida a mais humana de todas as questões - o homem é remetido para si mesmo, tornando-se alguém a quem a vida interroga alguém que a esta tem de responder, sendo responsável, assim, por sua vida.

Palavras-chave: Existência. Logoterapia. Vida, Sentido

* Psicólogo, atua junto à Prefeitura de Poços de Caldas, M.G.; Mestre em Psicologia da Saúde pela Universidade Metodista de São Paulo 


\begin{abstract}
Viktor Emil Frankl was a psychiatrist, Austrian founder of the school of Logotherapy, which explores the existential meaning of the individual and the spiritual dimension of existence. The authenticity of the work proposed by the author in question has its foundation brought in his experience in four Nazi concentration camps. The Logotherapy part of the spiritual dimension to address its relationship with other dimensions of life. Studies with specific situations of the sphere of the individual's existence without neglecting or denying the conflicts be they expressed by somatic or psychological . She is a centered psychotherapy sense, and considers his task to help the patient find meaning in his life becoming the primary motivating force in humans. Have to be found by the person, but not within it, because it would go against the law of self transcendence of human existence. As unique and specific as the actual situation is, therefore, the meaning inherent in it. The person who seeks Him in every situation is equally unique and unrepeatable. When trying to answer the question of the meaning of life - the most human of all issues - the man is left to himself, becoming someone to whom life questions, someone who has to respond to this, thus being responsible for your life .
\end{abstract}

Keywords: Existence; Logotherapy; Life; Sense.

\title{
Introdução
}

A busca pelo sentido da vida é uma atividade natural do ser humano. Somente ele é capaz de se interrogar pela sua existência e discutir os problemas do ser. O homem é um ser que procura sentido por participar da história e, na história, construir vida e dar sentido a ela. Na tentativa de conceder ao homem a sua dimensão de liberdade, de missão e de transcendência diante da catástrofe em massa da ideologia, do imperialismo cultural e da coerção psicológica que determinam a consciência do homem Victor Frankl criou uma logoterapia capaz de levar o homem a se interrogar pela sua própria pessoa e descobrir o sentido último de cada ação e de toda sua existência. Por isso, ele pode ser conhecido como o "médico da doença do século XX", a saber: o vazio existencial.

Assim, o objetivo do texto em questão é o de discutir a possível contribuição da logoterapia para o encontro com o sentido no mundo contemporâneo. Isto é, analisar a forma como Frankl concebe o 
mundo, o homem e uma prática terapêutica. O texto inicia tal análise com uma breve exposição sobre a visão de homem da logoterapia, a partir daí, explicita os conceitos base da logoterapia e por fim, a contribuição de tal olhar na prática do encontro, fenômeno este capaz de despertar sentido na vida de quem se propõe a experimentar uma realidade dotada de possibilidades, porém aberto para e não só na expectativa dê.

\section{Visão de homem e embasamento filosófico da Logoterapia}

Perceber homens e mulheres na sua totalidade é o objetivo da Logoterapia de Frankl, fundamentada na origem do ser humano. O autor tem como ponto de partida a compreensão do homem como um ser bio-psico-sócio-espiritual, capaz de superar qualquer tipo de sofrimento e que necessita de liberdade.

Segundo Coelho Jr e Mahfoud (2001), para Frankl, homem e animais são constituídos por uma dimensão biológica, uma dimensão psicológica e uma dimensão social, contudo, o homem se difere dos animais porque faz parte de seu ser a dimensão noética, ou seja, espiritual. Em nenhum momento o homem deixa as demais dimensões, mas a essência de sua existência está na dimensão espiritual. Neste sentido, Frankl, (1998) expõe a dimensão noética que é considerada superior às demais, sendo também mais abrangente, porque inclui as dimensões inferiores - o que garante a totalidade do homem

O conceito deste neuro-psiquiatra sobre o ser humano se contrapõe ao pensamento freudiano e adleriano, segundo os quais o homem estaria subjugado à busca por prazer e poder, respectivamente. Mais especificamente, na teoria freudiana o aparelho psíquico do homem é entendido a partir da divisão em três instâncias: o id, o ego e o superego, sendo o ego o responsável pela mediação dos interesses do id (composto por dois grupos de pulsões, que seriam: os instintos de vida e os instintos de morte/destruição) e do superego (instância psíquica responsável pelos valores, pela consciência moral, pela introjeção das regras sociais e do mundo externo. Muitos consideram essa visão freudiana do homem como sendo pessimista, pois esse homem dividido em três instâncias viverá sempre em conflito consigo mesmo e com o mundo, pois na maioria das vezes há uma 
contradição entre os desejos instintuais e aquilo que é permitido socialmente. Essa ideia é amplamente abordada pelo autor no livro “O Mal-Estar na Civilização” (FREUD, 1930 [2010]).

Já a teoria Adleriana apresenta uma visão holística do ser humano. Segundo Sommers-Flanagan e Sommers-Flanagan (2006), Adler não acreditava em subdivisão do indivíduo em partes funcionais. Para ele, há a unidade do pensamento, do sentimento, da atuação, das atitudes, dos valores, da mente consciente e inconsciente. Adler acreditava que o sujeito como um todo toma decisões pelas quais é inteiramente responsável; e a idéia de uma entidade id ou instinto que busca a gratificação separadamente não é compatível com as suas ideias, fundamentadas sobre o holismo.

Além disto, esses mesmos autores Sommers-Flanagan e Sommers-Flanagan (2006) entendem que Adler conceituou a "atitude para a vida", ou seja, o ser humano é ativo e responsável por suas decisões. Dessa maneira, Adler rompe com o determinismo freudiano e se aproxima das abordagens existencialistas e fenomenológicas. Porém, ele não rompe completamente com o determinismo, uma vez que na sua teoria é postulada a existência de uma força motriz humana básica: o esforço pela superioridade; ou seja, o esforço básico não representa uma necessidade de dominar os outros e sim, um esforço constante para superar a si mesmo e suas fragilidades. Ainda de acordo com esses autores, Adler crê que o ser humano tem a potencialidade de desenvolver-se tanto para o "bem" quanto para o "mal", não sendo nem pessimista, nem otimista quanto à natureza humana.

A importância de conduzir o homem à consciência do sentido e dos valores é a principal divergência tanto entre a logoterapia e a psicologia individual adleriana, quanto entre a logoterapia e a psicanálise freudiana, haja vista que a psicologia individual privilegia o ser humano no tocante ao seu ego e Freud delimita os atos e valores humanos sob a ótica da libido. Apesar destas divergências, Frankl considerava válido e imprescindível o fato de que estas correntes pretendiam conduzir o indivíduo à consciência, ou seja, ao juízo de valores quanto à sua responsabilidade com os vínculos sociais e os instintos.

Para o autor da Logoterapia, a frustração que aflige o homem hodierno, em oposição ao que acontecia na época de Freud, está re- 
lacionada ao existencialismo e não à sexualidade. Para Frankl (1991) sofre-se de maneira diferente ao que acontecia no tempo de Adler, uma vez que agora os conflitos humanos não mais se restringem ao id e ao ego, como têm embasamento, também, nos conflitos de ordem moral e existencial: "atualmente, o ser humano é preenchido pelo sentimento de vazio existencial, seguido de um sentimento de inferioridade, o qual é menos frequente do que a idealização de uma falta de sentido" (p. 155). Para o autor, no contexto contemporâneo o ser humano sente sua inconstância interior, seu vazio; porém não se dedica à busca do sentido para o que sente, deixando de lado a necessidade de consolidar seus alicerces existenciais e de compreender o porquê de sua existência.

Esta visão de homem da Logoterapia sofreu influência da abordagem humanista e da psiquiatria existencial. Para a abordagem humanista, o homem é compreendido em sua totalidade, de maneira holística. Além disto, pode-se dizer que a psicologia humanista baseia-se nas seguintes características do ser humano: liberdade, criatividade, autonomia, enfoque nas relações interpessoais e responsabilidade pessoal (BÜHLER, 1975).

A Logoterapia tem um caráter humanista, o que significa dizer que há possibilidade de correlacioná-la com outras abordagens, como a Centrada na Pessoa, de Carl Rogers que segue essa mesma perspectiva. Embora Frankl admita que essa e outras correntes humanistas tenham influenciado o desenvolvimento do seu trabalho, ele procurou distingui-lo das mesmas. Tanto que Viktor Frankl contesta o humanismo, o qual defende a capacidade de auto - realização do ser humano em si mesmo, afirmando que o homem somente será capaz de atingir seu objetivo de encontro de um sentido para a vida ao sair de si, ou seja, transcender, já que o sentido está presente em alguém ou em algo, ou seja, encontra-se no mundo. Sendo assim, o homem deve visar a auto-transcendência para a realização. Frankl (1989) critica a posição dos existencialistas que crêem em um sentido da vida que é construído pela pessoa, já que para Viktor Frankl, segundo Kroeff (2011), o sentido não é constituído, pois já existe no mundo.

Assim, a Logoterapia é caracterizada pelo foco no aspecto humano numa abordagem fenomenológica, outra influência filosófica 
de Frankl. Ressalta-se que Frankl dialoga com Heidegger, muitas vezes questionando seu pensamento, já que para este não há partes como soma e psique, mas uma totalidade que é a existência. A angústia é a condição existencial de vazio, o fato de que todos os significados para o mundo e as coisas não são dados em si, mas construídos pelo homem e por isso mesmo em constante mutação. A crítica de Frankl em relação a Heidegger é que o filósofo existencialista não menciona a capacidade humana para a transcendência no estado espiritual, ao contrário de Frankl, que já focaliza nesta dimensão humana. A dimensão noética é desconsiderada na análise heideggeriana do existir humano. Sendo assim, a Logoterapia procura ir além do pensamento Heideggeriano ao se propor a pensar em algo além da angústia, ou seja, que transcende a esta.

O próprio Frankl (1992) explica a transcendência humana compreendendo-a como "o verdadeiro sentido da vida" que há de ser desvelado no mundo e não dentro da pessoa ou de sua psique. Ao que Viktor Frankl chama de "característica constitutiva de a auto-transcendência da existência humana". Com isso o autor entende que o ser humano sempre busca ou e se dirige para algo ou alguém diferente de si mesmo - seja um sentido a realizar ou outro ser humano a encontrar. Quanto mais a pessoa esquecer de si mesma - dedicando-se a servir uma causa ou a amar outra pessoa - mais humana será e mais se realizará.

Assim, a auto-transcendência está relacionada às experiências e fatos vividos. Deste modo, o ser humano, ao encontrar com o outro, é capaz de atribuir sentido à vida, encontrando-se também consigo. Assim, o ser humano somente alcança sua auto-realização como um efeito colateral da auto-transcendência - ou seja, a auto-realização está relacionada com a transcendência, pois é somente quando o ser humano sai de si para ir ao encontro do outro que o mesmo encontra o sentido de maneira realizadora.

\section{Principais conceitos da Logoterapia}

Após descrever as raízes filosóficas da Logoterapia, se torna imperioso descrever a teoria de Viktor Frankl em seus principais conceitos. Desta forma enfatizaremos a noção de sentido da vida, a 
noção de existência, a noção de liberdade e a ideia de inconsciente espiritual ou noético, explorados a seguir.

Um conceito central para esta teoria é o de "sentido da vida", que não está no indivíduo, e por essa razão precisa ser sempre procurado na relação com o mundo. O ser humano é um ser em construção permanente, ou seja, ele interage com a sua vida, buscando um sentido para sua existência. Segundo Xausa (1990), esta busca do sentido é uma experiência na qual o ser humano percebe que vale à pena viver e, ao mesmo tempo, o seu processo de descoberta é ele mesmo constituinte da experiência de sentido. Logo, o mesmo é capaz de interrogar essa existência e discuti-la ao longo do seu desenvolvimento. Para Carrara (2016) entre as contribuições de Frankl para a Psicologia está a descoberta da "vontade de sentido", considerada a motivação primária no ser humano e não apenas racionalização secundária de impulsos instintivos. Ao buscar o sentido de sua própria existência humana, o observador, antes tão ocupado em ver o mundo ao seu redor, fragmentando-o, tem a oportunidade de ver a si mesmo, percebendo sua dimensão noética transcendente, acrescentando assim um novo sentido ao mundo que observa. Moreira e Holanda (2010) expressam este movimento do indivíduo em direção ao âmbito noético pela seguinte frase: "É como o olho, que só pode cumprir sua função de ver o mundo enquanto não vê a si próprio" (p.346).

Nesse sentido, Moreira e Holanda (2010) articulam o pensamento de Frankl às questões já abordadas por Kierkegaard, autor que também influenciou Frankl. Enquanto para Kierkegaard, o sentido da vida é "o quê", para Frankl o mesmo é "para quê". Esses autores afirmam que Kierkegaard utiliza metáfora para entender o esforço humano na busca pela felicidade: - a porta da felicidade abre-se "para fora", ou seja, ela fecha-se exatamente para quem tenta empurrá-la para dentro( p. 345). Entretanto, Frankl, aponta para uma dimensão que só Deus pode mensurar, na fidelidade ao sentido da existência, à missão do ser humano sobre a face da terra.

Assim, Frankl entende que o ser humano só se faz 'ser humano' quando ele se dedica a uma determinada tarefa, não se centrando somente em si e prestando serviço a algo ou alguma pessoa. "O 
sentido tem um caráter objetivo de exigência e está no mundo, não no sujeito que o experiência." (MOREIRA; HOLANDA, 2010, p. 346).

Frankl dá ênfase tanto à importância de se encontrar um sentido para a vida quanto às consequências da falta de sentido, situação que ele denomina 'vazio'. Mas, Frankl (1998) não entende esse "vazio" como patologia ou uma neurose. Ele entende como uma prova da humanidade da pessoa; todavia este sentimento pode sim causar uma reação patológica.

$\mathrm{O}$ autor ainda reflete acerca dos motivos que levam o sujeito à falta de sentido quando explica que entre tudo aquilo que parece tirar o sentido da o sentido da vida humana está, não só o sofrimento, mas a morte (FRANKL, 1998).

Outros conceitos importantes para a Logoterapia são os de liberdade e responsabilidade. Responsabilidade, na perspectiva de Frankl, diz respeito à capacidade de responder pelos atos realizados, distanciando-se do conceito vulgarmente relacionado a um caráter moralista, no qual o ser humano seria coagido a agir de acordo com normas introjetadas; ou seja, responsabilizar-se se refere a assumir a própria liberdade e se posicionar perante si mesmo e a sociedade. Sendo assim, cabe ao homem em sua liberdade efetiva para se posicionar no mundo, manifestando, então, a "irrepetibilidade e caráter de algo único" constituinte de cada homem (FRANKL, 1989).

Falar de existência, na sua dimensão espiritual, que é o foco da Logoterapia, é falar, sobretudo do "ser-responsável" e do "ser humano consciente de sua responsabilidade" (FRANKL, 1992). Trata-se não de exercer suas vontades a despeito das condições biológicas, psicológicas e sociais - às quais todo homem está submetido - mas da liberdade para uma tomada de posição diante de todas as circunstâncias cotidianas ou excepcionais. O homem sempre estará exposto a estímulos e determinações ambientais de diversas ordens, mas essa liberdade descrita por Frankl refere-se à maneira criativa e própria de cada indivíduo, expressa no momento em que responde aos estímulos e determinações.

$\mathrm{O}$ autor entende que a transitoriedade da existência humana não lhe subtrai o sentido; todavia, entanto a transitoriedade constitui uma responsabilidade, porque tudo vai depender do quanto nos conscientizarmos das possibilidades essencialmente transitórias. 
O ser humano está constantemente fazendo uma opção diante da massa de potencialidades presentes (FRANKL, 1998).

Estas concepções de liberdade/responsabilidade foram vislumbradas nos campos de concentração nazistas nos quais Viktor Frankl foi prisioneiro e pôde observar, conforme ele mesmo afirmara (FRANKL, 1998), as diversas maneiras de enfrentar e lidar com aquela circunstância inevitável e com o sofrimento dela decorrente, a que todos estavam submetidos. Naquela situação, cada pessoa posicionava-se de uma maneira diferente: havia quem se jogasse nas cercas eletrificadas, outro se deixava levar pela impotência e, deprimido, adoecia mais facilmente, outro ainda decidia resistir até o fim porque tinha a esperança de que algo o esperava ao sair dali - uma pessoa a amar, uma obra a realizar, um Deus a quem servir. Nesta liberdade de resposta, aqueles prisioneiros colocavam-se diante das situações conferindo sempre a elas um sentido pessoal, um motivo ou razão pela qual valesse a pena continuar vivendo. A dimensão espiritual mostra-se, portanto, como uma dimensão não-determinada, mas determinante da existência.

Viktor Frankl afirmara que no campo de concentração parecia que todos os objetivos comuns da vida estavam desfeitos. Havia sobrado "a última liberdade humana" - a capacidade de escolher a atitude pessoal que se assume diante de determinado conjunto de circunstâncias. Esta liberdade última, já estudada pelos antigos estóicos e pelos existencialistas, assume um vívido significado (FRANKL, 1988; 1991).

Isso ressalta a ideia de que o ser humano possui em si a habilidade de conquistar a sua própria liberdade, mediante quaisquer circunstâncias - sejam estas de origem psíquica ou proveniente do coeficiente transcendental ou inconsciente espiritual (noética). Em relação ao sofrimento, o autor questiona a capacidade existente no ser humano de reerguer-se diante de qualquer conflito que a vida vier a lhe impor.

É importante ressaltar que não são apenas nos momentos mais difíceis, ou seja, aqueles de sofrimento, que esta afirmação do ser humano - através da liberdade e responsabilidade - encontra um sentido para sua vida. No âmbito da clínica, Frankl (1989; 1991) observou que outros dois caminhos se apresentam como possibili- 
dade de experiências constitutivas de sentido: o trabalho, onde se cria algo para alguém; e o amor, onde duas pessoas se encontram existencialmente em sua originalidade e se tornam insubstituíveis uma para a outra. $\mathrm{O}$ trabalho pode ser experiência de transcendência de si na qual se vivencia um valor da própria pessoa ligado à utilidade, podendo chegar a constituir sentido. De maneira semelhante, também o amor possibilita a experiência de transcendência, porém vivida na intersubjetividade, ou seja, o encontro evidencia o valor do "caráter de algo - único" das pessoas.

Assim, quanto à importância do inconsciente espiritual, Coelho Jr e Mahfoud (2001), explicam que no livro 'A Presença Ignorada de Deus' de 1992, Frankl apresenta o conceito de inconsciente espiritual ou noético, o qual diz respeito sobre à possibilidade da espiritualidade se manifestar no inconsciente, dizendo "a pessoa profunda, ou inconsciente." Desta maneira, o autor explicita que o conceito da dimensão espiritual está relacionado ao inconsciente e ainda ressalta que uma das características primordiais desta dimensão está associada à "autotranscendência", ou seja, o ser humano é constituído de uma instância à qual Frankl se refere como intencionalidade, que o dirige para algo ou alguém fora de si mesmo. Apenas por meio desta autotranscendência é que o espírito se realiza: somente na execução de atos espirituais - conduzidos a algo ou alguém manifestando-se no seu real que transcende a este, constituindo-se, assim, como "realidade de execução."

No que se expressa como "realidade de execução", Frankl quer dizer que o ser humano fica imerso em sua própria existência concreta para executar seus atos espirituais, tornando-se impossível refletir sobre sua verdadeira essência. Neste momento o homem entra em um estágio quase que inconscientemente extasiado em busca de seu ideal, o que não lhe cabe, perceber-se neste. Assim, a existência noética torna-se impossível de reflexão no momento em que se realiza, por conta da autotranscendência.

Frankl (1992), ao observar fenômenos especificamente humanos através de um processo indutivo, ou seja, fenomenológico, chega a conclusões que melhor caracterizam o inconsciente noético. Os fenômenos escolhidos por ele foram a consciência moral, o amor e a arte. A respeito do primeiro fenômeno citado, a moral, Frankl acredita que 
o caráter de "dever" próprio da consciência moral não poderia vir do homem, mas sim da transcendência - algo maior do que ele - por se compor como uma palavra segura, de "autoridade," que orienta o almejado de modo eficaz em direção à realização do sentido da vida, revelando-se como uma característica humana, ontológica.

Ainda a respeito do inconsciente noético transcendente, Coelho Jr e Mahfoud (2001) afirmam que, na busca de compreensão da existência humana, Frankl se deparou com o fato de que esta dimensão manifesta-se através da intuição, para a qual voltamos agora nossa atenção. Para que o homem siga a intuição é necessário que considere algo em si que lhe diz o que fazer, que considere a voz da consciência moral, percebida por ele como algo que não vem de si mesmo, percebida como algo transcendente "extra-humano" e capaz de orientá-lo.

A relação com a transcendência pode ser apreendida pelo indivíduo, no auge da plenitude, como uma dialética na qual o transcendente é considerado como um "Outro." A este homem transcendente Frankl denomina de homo religiosus. Entretanto, este relacionamento com o Outro também pode estar obscuro para nós, inconsciente ou amordaçado, mas todo homem está sujeito a ele enquanto potencialmente humano. Frankl (1992), buscou o inconsciente noético, a partir da análise de sonhos e constatou a presença de conteúdos religiosos reprimidos, mesmo em pessoas céticas, percebendo que a religiosidade poderia ser ocultada psicologicamente diante do eu consciente. Estes trabalhos com análise de sonhos confirmaram que pode haver no inconsciente noético uma religiosidade no sentido de um relacionamento inconsciente com o Outro, de uma relação constante com o transcendente, considerada por Frankl como uma "fé inconsciente".

Retomemos, agora, o tema da consciência moral, entendida como um fenômeno próprio do homem. A consciência moral, ou melhor, a voz da transcendência, guia o homem em suas respostas às perguntas que a vida lhe faz através de situações concretas. No momento em que responde, o homem pode elaborar a vivência de diálogo com a consciência moral, podendo atribuir a este diálogo uma característica de experiência religiosa.

Considerando psicologicamente, o homem religioso é aquele que, ao atender ao falado, experimenta a vivência de alguém que lhe fala, 
sendo, portanto, homem de ouvido mais agudo que o homem não religioso: no colóquio com sua consciência - essa conversação mais íntima que se dá a sós consigo mesmo - o seu Deus é o interlocutor que o acompanha (FRANKL, 1992, p. 97) O homem religioso é capaz de assumir a sua vida como uma missão a ser cumprida, experienciando a instância de onde a missão lhe vem, e como busca do encontro com esta instância. A vida deixa transparecer nestes homens a presença daquele que lhes confere a missão. Este é o homo religiosos, o homem que foi capaz - segundo Frankl - de completar a dinâmica ontológica. Nele, ser responsável e ser consciente se dão simultaneamente.

A experiência religiosa, assim caracterizada, é tão importante no caminho da busca do sentido da vida, que Frankl chega a afirmar que o homem irreligioso não foi capaz de dar este último passo - o da experiência religiosa - escolhendo ficar no meio deste caminho. Caminhando rumo ao sentido, o homem irreligioso parou antes do tempo, pois não foi capaz de perguntar para além de sua consciência (FRANKL, 1992).

A experiência religiosa, portanto, está agregada na caminhada para uma vida plena de sentido, na qual o homem explora a força de sua dimensão espiritual. Eis então a relação entre a noética consciente e a noética transcendente: é porque o homem apresenta uma dimensão espiritual, transcendente, que ele se sente atraído pela religiosidade.

\section{O sentido da Logoterapia para os dias atuais}

No sentido clínico, pode-se considerar pertinente a ênfase de Frankl na questão da auto-transcendência, pois o ser humano vai muito além das capacidades que demonstra superficialmente. Em sua época, esta crença na capacidade do ser humano, em si mesma, já era revolucionária, pois durante a guerra a sensação de desesperança era acompanhada do discurso da automatização que destituía as individualidades em prol do Estado totalitário. Assim, a questão do sentido da vida que Frankl, enquanto médico apresentava junto às pessoas, contrapunha-se diretamente a lógica racionalizada da cultura totalitarista. Ao auxiliar as pessoas no processo de encontrar um sentido para a vida, de se questionar sobre a religiosidade, a questão da morte, a questão das perdas, Frankl fornecia um espaço 
de reflexão sobre a experiência, que ele compreendia como campo privilegiado da psicoterapia.

Embora grandemente marcada pelo contexto da Alemanha nazista, a obra de Frankl apresenta uma significativa atualidade. Muitas das questões abordadas pelo autor fazem parte tanto da condição humana em si quanto dos problemas encontrados nas experiências contemporâneas.

Para continuar esta discussão, faz-se necessário abordar a questão da vida humana na contemporaneidade. São características do tempo atual o mundo mecanicista, onde se dá ênfase ao tecnológico em detrimento de relações interpessoais mais profundas. Neste contexto, o ser humano parece ter perdido o sentido - são tantas informações e conhecimentos disponíveis que o ser humano não consegue se localizar. Além disto, existem inúmeros outros fatores que contribuem para a fragmentação do sentido da vida humano na era tecnológica, robótica e mecanicista: a ênfase na estética, a busca por um padrão de beleza inatingível; no bem-estar, chegando a ponto de se considerar negativas e patológicas as manifestações comuns da vida humana como a tristeza e a ansiedade - o que leva, entre outras conseqüências, à medicalização da vida. Diante deste contexto, brevemente descrito, pode-se perceber que a sociedade encontra-se adoecendo e fragilizada. Como aponta Homem (2003)

A cultura pós-moderna é caracterizada por três pontos principais: o reinado quase absoluto da sagrada imagem, ápice de um processo mais amplo no qual a indústria cultural passou a reinar quase absoluta, engendrando a sociedade dita do espetáculo; a objetificação crescente do sujeito e de certa maneira inevitável, irmã da mercantilização que invade todos os domínios da experiência humana; a fetichização que dá a sustentação da mercadoria como objeto de consumo, objeto consumível e nunca atingido, sempre pronto para ser o próximo de uma cadeia simbólica infinita e sempre mais cara [....] (p.2 e 3).

Nesta situação, as pessoas parecem fazer muitas coisas, viver muitas experiências, mas sentem que não existe um sentido para tudo o que fazem. Além disto, sentem-se vazias - têm constantemente pressa para fazer muitas coisas, mas quando param para avaliar 
a si mesmos, sentem-se vazias. Esse vazio provoca uma sucessão de emoções contraditórias, podendo levar a doenças como a depressão.

Neste contexto, a Logoterapia pode contribuir para o entendimento, pela psicoterapia do homem contemporâneo, pois busca justamente o que falta em muitas experiências humanas na atualidade: um sentido para a vida. Busca resgatar os sentidos que cada um constrói para sua vida, com a intenção de tornar o homem consciente da sua própria história e dos sentidos que foram sendo construídos ao longo do tempo, e que estavam camuflados. Ou seja, a Logoterapia pode auxiliar a pessoa a encontrar um sentido para sua vida, a tomar posse da sua história, buscar uma consistência para si a partir do sofrimento.

Nesse sentido, ela oferece um espaço de reflexão que falta no dia-a-dia das pessoas no mundo pós-moderno. Hoje, neste mundo fragmentado, as pessoas muitas vezes perdem o contato com as suas raízes, a sua cultura - isto contribui para a perda de sentido.

A partir da obra de Frankl podemos, também, atualizar a discussão acerca da questão da transcendência, uma das características humanas mais diretamente ligadas ao sentido da vida, pois para o autor o ser humano possui um impulso para buscar algo para além de si, força que pode construir novo sentido para que o homem se conecte à sua totalidade como bio-psico-sócio e espiritual. Muitas vezes, na superficialidade da vida cotidiana, o homem acaba por viver em uma constante angústia, que podemos chamar de vazio existencial. Este sentido do sofrimento está agregado com a questão noética, que Frankl denomina neurose noogênica. Para que o homem possa atribuir essa força que existe no seu âmago, pode-se conseguir este objetivo através da fé - a qual, inclusive, dá um sentido diferente para uma das questões que mais aflige o ser humano em qualquer contexto histórico: a morte. Importante destacar que, em sua obra, Frankl não recomenda nenhuma religião ou confissão constituída, muito menos alguma igreja em especial. A todo tempo ele remete o leitor às suas próprias preferências e escolhas. Para Pereira (2009) é bem óbvio que uma psicoterapia que se funda na noção de liberdade espiritual não pode ser axiologicamente neutra; assim, a prática clínica deve trabalhar, "Weltanschauung" do paciente, (conjunto ordenado de valores, impressões, sentimentos 
e concepções de natureza intuitiva, anteriores à reflexão) de modo que a psicoterapia deve valorar, estabelecer valores éticos como tais e servir à ética.

Pelo fato de a Logoterapia tratar de questões profundamente humanas, que jamais deixarão de ser "atuais", pois são inerentes à condição humana (solidão, angústia, morte, sofrimento), conclui-se que esta modalidade de terapia ainda é pertinente nos dias atuais.

\section{Referências}

BÜHLER, C. Psicologia existencial e humanista: resposta a desafios contemporâneos. In: GREENING, T. C. (Org.) Psicologia Existencial-Humanista. Rio de Janeiro: Zahar, 1975, p.31-65.

CARRARA P. S. Espiritualidade e saúde na Logoterapia de Victor Frankl. Interações - Cultura e Comunidade, Belo Horizonte, v.11, n.20, p.. 66-84, JUL./DEZ, 2016

COELHO JR, A.G; MAHFOUD, M. As dimensões espiritual e religiosa da experiência humana: distinções e inter-relações na obra de Viktor Frankl. Psicologia USP, v. 12, n. 2, p. 95-103, 2001. Disponível em http://www.scielo.br/scielo. php?script=sci arttext\&pid=S0103-65642001000200006\&lng=en\&nrm=iso. Acesso em: nov 2016

FRANKL, V. E. Psicoterapia e sentido da vida. São Paulo: Quadrante, 1989.

FRANKL, Victor. Em busca de um sentido: Um psicólogo no campo de concentração. Petrópolis: Vozes, 1988.

FRANKL, V. A psicoterapia na prática. Tradução C. M. Caon. Campinas: Papirus, 1991.

FRANKL, V. A presença ignorada de Deus. Petrópolis: Vozes, 1992.

FRANKL, V. E. Senso e valori per l'esistenza: la risposta della logoterapia. Roma: Città Nuova Editrice, 1998. (Original de 1969).

FREUD, S. O mal estar na civilização. (1930). In: . O mal-estar na civilização e outros textos (1930-1936). Obras completas de Sigmund Freud Vol XVIII, eBook Kindle tradução de Paulo César de Souza, 2010.

HOMEM, M. L. Entre próteses e prozacs O sujeito contemporâneo imerso na descartabilidade da sociedade de consumo. Estados Gerais da Psicanálise: Segundo Encontro Mundial, Rio de Janeiro, RJ, 2003. Disponível em: http://egp.dreamhosters. com/encontros/mundial ri/download/4 Homem 135161003 port.pdf Acesso em 12 out 2016. 
KROEFF, P. Logoterapia: uma visão da psicoterapia. Revista da Abordagem Gestaltica, v. 17, n. 1, p. 68-74, jan./jun. 2011.

MOREIRA, N; HOLANDA, A. Logoterapia e o sentido do sofrimento: convergências nas dimensões espiritual e religiosa. Psico-USF, v.15, n.3, p. 345-356. set/dez, 2010.

PEREIRA, I.S. A ética do sentido da vida na Logoterapia. 125 fls. Dissertação (Mestrado em Filosofia). Programa de Pós Graduação em Filosofia da Universidade Federal do Ceará, 2009.

SOMMERS-FLANAGAN, J; SOMMERS-FLANAGAN, R. Abordagem psicanalítica, analítica breve, de relações objetais e interpessoal. In: SOMMERS-FLANAGAN, J; SOMMERS-FLANAGAN, R (orgs). Teorias de aconselhamento e de psicoterapia. Rio de Janeiro: LTC, 2006. Cap. 2, p.21-30

XAUSA, I.A.M.. A Psicologia do sentido da vida. Petrópolis: Vozes, 1990.

Contato do autor:

Cristiano J. Andrade - email : cristianoandradepsico@gmail.com

Texto recebido em: 08/08/2017

Aceito em 29/09/2017 